\title{
ПРИМЕНЕНИЕ ПРЕПАРАТА БОТУЛИНИЧЕСКОГО ТОКСИНА ТИПА А В ЛЕЧЕНИИ МИОФАСЦИАЛЬНОГО БОЛЕВОГО СИНДРОМА
}

\author{
*Девликамова Ф. И., Рогожин А. А. \\ Кафедра неврологии и мануальной терапии Казанской государственной медицинской академии, \\ Казань, Татарстан, Россия.
}

\begin{abstract}
Применение ботулотоксина типа А в лечении миофасциального болевого синдрома имеет множество теоретических предпосылок, но клиническая эффективность остается недоказанной до настоящего времени. Обследовано 12 пациентов не старше 50 лет с активным МТ3 в горизонтальной порции трапециевидной мышцы, куда и вводилось ботулотоксин типа А. В зоне МТЗ проводилась стандартная игольчатая ЭМГ и ЭМГ одиночного мышечного волокна до введения препарата, через неделю, 1, 4 и 12 месяцев. Через 1 месяц выявлялось укорочение длительности ПДЕ и смещение гистограммы распределения потенциалов по длительности влево. Через 4 месяца после введения препарата намечалась тенденция к восстановлению параметров ПДЕ к исходным величинам. Параметры ПДЕ через 1 год после инъекции не отличались от исходных. Таким образом, проведенное исследование по продемонстрировало положительное действие ботулотоксина типа А на электрофизиологические параметры в МТ3, отражающие функциональное состояние периферического нейромоторного аппарата.

Ключевые слова: миофасциальный болевой синдром, триггерные пункты, ботулиниче-ский токсин типа А, электромиография, двигательная единица, мышечное волокно.
\end{abstract}

$\boldsymbol{\Psi} \boldsymbol{a}_{\text {к проблеме миофасциальной боли. }}^{\text {протяени века не угасает интерес }}$ Практическое значение изучения механизмов миофасциального болевого синдрома (МБС) весьма значимо из-за неразрывной связи поиска путей лечения и взглядов на патогенез.

В 1994 году впервые был описан терапевтический эффект БТА у больных с миофасциальным болевым синдромом. Это были пилотные исследования, включавшие только двоих и шестерых пациентов [16, 21]. Первые результаты были многообещающими и положили начало дальнейшим попыткам применять ботулотоксин типа А в лечении миофасциальной боли. На сегодня, наибольшими по числу включенных пациентов являются исследования F.M.Ferrante с коллегами (132 пациента) и H.Göbel с коллегами (144 пациента). В исследование F.M.Ferrante включались пациенты с МТ3, вызывающие боль в шейном отделе и области плечевого пояса. Эффект инъекции БТА в МТЗ сравнивался с эффектом инъекции плацебо. После инъекции проводился мифофасциальный релиз. Также пациентам разрешалось принимать анальгетики. На визитах через 1, 2, 4, 6, 8 и 12 недель после инъекции, сравнивались

*e-mail: fdevlikamova@mail.ru интенсивность боли по ВАШ, болевой порог и количество анальгетиков принимаемых пациентами. Исследование не выявило различий в эффективности БТА и плацебо [26]. В исследование H.Göbel были включены пациенты с миофасциальной болью в верхней части спины. Исследование показало большую эффективность ботулотоксина типа А, по сравнению с плацебо (физиологическим раствором) [30]. Таким образом, два наиболее масштабных на сегодня исследования имеют противоположные результаты. Отличием этих работ является разная распространенность МБС у включенных пациентов. В исследование F. M. Ferrante были включены пациенты не более чем с 5-ю МТЗ, в то время как в исследование H.Göbel, пациент мог быть включен только при наличии 10-ти или более МТЗ. В систематическом обзоре об эффективности ботулотоксина типа А, представленном в 2006 году, делается вывод о недостаточности данных для суждения о целесообразности применения данного метода лечения. [17]. К такому же выводу приходят R.Gerwin - в обзоре исследований применения ботулотоксина в лечении миофасциальной боли, а также А.Soares с соавторами. [27, 47]. 
Электрофизиологические и фармакологические исследования W. C. Wiederholt (1970) демонстрировали, что ЭМГ активность, подобная шуму, представлена потенциалами концевых пластинок и может быть зарегистри-рована только из измененных КП, которые разрушены механически или биохимически. Таким образом, локус шума концевой пластинки в зоне МТ3, вероятно, связан с измененными потенциалами в зоне двигательных КП. Патологические КП могут вызывать сенситизацию ноцицепторов и боль в зоне MT3.

При использовании ботулотоксина в лечении тонических напряжений мышц, существует ещё один механизм действия, а именно, влияние на интрафузальные мышечные волокна. Электромиографически было показано снижение афферентной импульсации, исходящей из интрафузальных мышечных волокон, а гистологически была выявлена их атрофия [16].

\section{МАТЕРИАЛ И МЕТОДЫ}

Материалы настоящего исследования получены в результате проведения клинико-нейрофизиологического обследования 12-ти пациентов с мио-фасциальным болевым синдромом в возрасте от 24-х до 50-ти лет; продолжительность симптомов заболевания составила от 3-х до 15-ти лет. У одной пациентки причиной формирования МТ3 явилось изменение двигательного стереотипа в результате выраженной вертебральной деформации, у остальных - некоординированные статодинамические перегрузки.

Критериями включения в исследование являлись:

- наличие активного МТЗ в горизонтальной порции трапециевидной мышцы;

- отсутствие сопутствующей соматической патологии, актуальной на момент обследования;

- отсутствие онкологической патологии и патологии нервно-мышечного аппарата в анамнезе;

- верхний возрастной предел - 50 лет.
Все пациенты проходили стандартное неврологическое обследование с детальной оценкой алгических проявлений миофасциального болевого синдрома.

Препарат ботулинического токсина типа А и гемагглютинина вводили под контролем ЭМГ в МТЗ горизонтальной порции трапециевидной мышцы; по 50 ЕД (для препаратов по 500 ЕД БТА в ампуле), или 15 ЕД (для препаратов по 100 ЕД БТА в ампуле).

Двенадцать здоровых испытуемых, сопоставимых по возрасту и полу, составили контрольную группу.

На каждого больного составлялись "карта исследования больного" и "результаты проведения исследования по препарату БТА". Больные были полностью информированы о природе и механизме действия лекарственного препарата БТА, его эффективности и возможных побочных эффектах.

Всем больным проводилось комплексное нейрофизиологическое обследование, включающее игольчатую электромиографию с изучением нервно-мышечного соединения, двигательных единиц (ДЕ) в целом и мышечных волокон (МВ) - в отдельности. Состояние МВ и ДЕ скелетных мышц человека изучали различными электрофизиологическими методами: классическая игольчатая ЭМГ [20], ЭМГ одиночного мышечного волокна [49]. Исследования проводили в стандартных условиях на 4-х канальном электромиографе Keypoint фирмы Dantec/Medtronic (Дания/США), с помощью соответствующих игольчатых электродов той же фирмы.

Изучено 2400 ПДЕ скелетных мышц человека с использованием концентрических игольчатых электродов (внешний диаметр 0,45 мм, площадь отводящей поверхности 0,07 $\left.\mathrm{Mм}^{2}\right), 1140$ потенциалов и комплексов потенциалов отдельных мышечных волокон, принадлежащих изучаемым двигательным единицам мышцы, с использованием электродов с малой отводящей поверхностью (диаметр канюли 0,5 мм, отводящая поверхность 25 мкм). Во время каждого исследования, в обследуемой мышце регистрировали по 20 
различных потенциалов. Динамика изменения состояния ДЕ по мере развития патологического процесса, восстановления или утраты функции, оценивалась по результатам повторных обследований одних и тех же больных.

\section{РЕЗУЛЬТАТЫ И ИХ ОБСУЖДЕНИЕ}

Исследование выполнялось в течение года. Проводили клиническое исследование и нейрофизиологическую диагностику до введения препарата, и в динамике - через неделю, месяц, 4 месяца и год. Во время лечения препаратом БТА больным не назначалась другая терапия.

Клинически положительная динамика состояния больных намечалась к концу первой недели после введения препарата. К концу первого месяца отмечалось восстановление плотности мышечной ткани, практически нивелировался триггерный феномен. В течение четырех месяцев не отмечалось рецидива со стороны исследуемых мышц. Не наблюдалось также и формирования латентного МТЗ в данной области. По истечении 5 месяцев, у одной больной - после длительного психоэмоционального перенапряжения, и двух больных - после длительной статической физической нагрузки, наблюдалось появление болезненного мышечного уплотнения в этой зоне с минимальным триггерным эффектом, которое быстро удалось купировать с минимальными терапевтическими затратами. Клинически выявлено, что доза была достаточной и адекватной. Следует отметить, что генерализованной слабости мышцы после введения БТА в зону МТЗ не наблюдалось.

При электрофизиологическом исследовании в первую очередь оценивался шум концевой пластинки. Известно, что в норме мышца в состоянии покоя не генерирует никакой электрической активности, кроме фоновой активности зоны КП. Активность КП является физиологической по своей сути, склоняясь к чрезмерности в денервированных мышцах $[36,43]$. Высокая частота регистрации шума КП в МТЗ позволили ряду авторов [37, 44] высказать предположение о генерации фоновой активности измененными двигательными КП. Шум КП представляет собой экстраклеточные зарегистрированные миниатюрные потенциалы, являющиеся локальной деполяризацией мембраны концевой пластинки, вызванной спонтанным высвобождением квантов ацетилхолина. Раздражение маленьких внутримышечных нервных терминалей верхушкой электрода вызывает активность КП, которая состоит из двух компонентов: низкоамплитудного волнообразного шума КП и высокоамплитудных прерывистых спайков. Эти два компонента фоновой активности в зоне КП появлялись как вместе, так и независимо друг от друга; при этом, шум КП в МТЗ регистрировался значительно чаще, чем отдельные спайки. Сравнение электрических характеристик МТЗ различных мышц, не выявило каких-либо существенных отличий; по этой причине, полученные нами данные электрофизиологического изучения МТ3 трапециевидной мышцы, могут быть применены в обсуждении патогенеза миофасциального болевого синдрома $[8,5]$.

Фоновая активность в зоне КП, в виде шума КП, состояла из частых повторяющихся нерегулярных негативных потенциалов с частотой 20-40 Гц низкой амплитуды (10-50 мкВ) и 1-2 мс длительности, с характерным звуковым феноменом. Прерывистые спайки с амплитудой 100-200 мкВ и длительностью 3-4 мс, появлялись нерегулярно, от 5 до 50 импульсов в сек. Типичные потенциалы с начальным негативным отклонением, указывают, что спайки генерируются у верхушки регистрирующего электрода.

Было выявлено, что в МТЗ регистрировались, наряду с нормальными, - измененные по форме, несколько увеличенные по длительности и времени нарастания потенциалы КП.

Исследование области МТЗ в момент ее полного расслабления не выявило спонтанной активности МВ и ДЕ. Средние величины оцениваемых показателей зоны активного МТЗ до введения БТА (исходные значения), и их сравнение с нормой, представлены в таблице 1. 


\section{Сравнительный анализ средних величин (M士SD) параметров ПДЕ, регистрируемых в двигательной точке трапециевидной мышце здоровых людей и в МТ3}

\begin{tabular}{|l|l|l|l|}
\hline Параметры & Норма & Исходные значения & P \\
\hline Длительность ПДЕ, \% & $96,0 \pm 17,1$ & $94,78 \pm 13,05$ & $>0,05$ \\
\hline Амплитуда, мКВ & $890,7 \pm 436,8$ & $762,52 \pm 407,11$ & $<0,01$ \\
\hline Фазы ПДЕ & $3,4 \pm 0,5$ & $3,47 \pm 1,19$ & $<0,05$ \\
\hline Турны ПДЕ & $3,3 \pm 1,8$ & $3,97 \pm 2,16$ & $<0,01$ \\
\hline Латентность ОК ПДЕ, мс & $2,7 \pm 0,9$ & $2,33 \pm 1,12$ & $<0,01$ \\
\hline Длительность ОК ПДЕ, мс & $2,0 \pm 0,6$ & $2,30 \pm 0,93$ & $<0,001$ \\
\hline Терминальная длит. ОК ПДЕ, мс & $5,52 \pm 0,7$ & $5,63 \pm 1,51$ & $>0,05$ \\
\hline Фазы ОК ПДЕ & $1,6 \pm 0,4$ & $1,92 \pm 0,91$ & $<0,1$ \\
\hline Турны ОК ПДЕ & $1,3 \pm 0,4$ & $2,05 \pm 1,69$ & $<0,001$ \\
\hline Время нарастания ОК ПДЕ, мс & $3,4 \pm 1,0$ & $4,3 \pm 2,4$ & $>0,05$ \\
\hline
\end{tabular}

Проведенный анализ ПДЕ, регистрируемых в МТ3, выявил, что нормализованная длительность потенциала не отличалась от нормы, и 98\% всех ПДЕ имели длительность не более $\pm 30 \%$ от величины среднего показателя, принимаемого за 100\%. Величина амплитуды колебалась от 210 до 4825 мкВ (среднее значение - 965,52 797,11 мкВ). Амплитуда большинства потенциалов (88\%) была в пределах от 400 до 1500 мкВ. Процент потенциалов с высокой амплитудой (более 1000 мкВ) составил $35 \%$, и повлиял на показатель средней амплитуды ПДЕ, который выше среднего значения исследуемого параметра здоровой мышцы. В 65\% ПДЕ время нарастания позитивно-негативного отклонения не превышало 500мс. Характеризуя форму потенциалов, следует отметить, что в $82,1 \%$ случаев число фаз было в пределах нормы, тогда как в здоровой мышце этот показатель превышает 90\%. Полифазные потенциалы имели в большинстве случаев 5 фаз. Большинство псевдополифазных потенциалов имело $5(12,1 \%)$ или 6-7 (10,4\%) турнов. Обращает на себя внимание увеличение числа турнов спайкового (основного) компонента (ОК) ПДЕ в зоне локализации триггерного пункта $(1,85 \pm 1,69)$.

Таким образом, данные ЭМГ обследования у больных до начала проведения программы исследования выявили признаки, характерные для миофасциальной триггерной зоны $[8,14,6]$.
Представляется важным то обстоятельство, что в зоне пальпируемого МТЗ при электромиографическом обследовании, выявлено значительное увеличение турнов спайковой части потенциалов. Имеется значительное число работ, указывающих на высокую диагностическую значимость изучения количества турнов для характеристики состояния МВ. Количество турнов центральной спайковой части ПДЕ зависит от числа генераторов потенциала действия одной ДЕ, концентрирующихся в непосредственно прилегающей к электроду зоне, что отражает плотность МВ. Изменение плотности волокон является ранним признаком реорганизации ДЕ при нервно-мышечных заболеваниях и может влиять на число турнов ПДЕ.

Плотность мышечных волокон в МТЗ превышала показатели контрольной группы (2.05, SD 0.26; контроль - 1.40, SD 0.3, P<0.01). Регистрировались потенциалы отдельных МB с одним, двумя, тремя и четырьмя спайками. Отмечено увеличение межимпульсного интервала, по сравнению с контрольной группой [7].

Динамику нейрофизиологических изменений прослеживали на сроках 7 дней, 1 месяц, 4 месяца и год после введения препарата Результаты проведенных исследований представлены в таблицах 2-5.

Активная денервации скелетной мышцы, в которую был введен препарат, в виде спонтанной активности МВ, отмечалась на 7-й день. 
Таблица 2

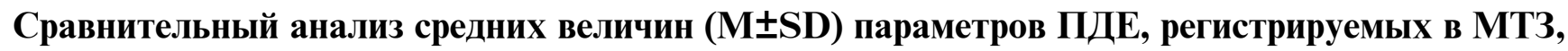
до и через неделю после введения ботулотоксина типа А

\begin{tabular}{|l|l|l|l|}
\hline Параметры & Исходные значения & $\begin{array}{l}\text { Через неделю } \\
\text { после введения }\end{array}$ & P \\
\hline Длительность ПДЕ в \% & $94,78 \pm 13,05$ & $91,64 \pm 16,24$ & $>0,05$ \\
\hline Амплитуда, в мкВ & $965,52 \pm 797,11$ & $867,80 \pm 719,06$ & $>0,05$ \\
\hline Фазы ПДЕ & $3,47 \pm 1,19$ & $3,41 \pm 1,26$ & $>0,05$ \\
\hline Турны ПДЕ & $3,97 \pm 2,16$ & $3,70 \pm 1,85$ & $>0,05$ \\
\hline Латентность ОК ПДЕ, мс & $3,03 \pm 1.12$ & $3,05 \pm 0,86$ & $>0,05$ \\
\hline Длительность ОК ПДЕ, мс & $2,30 \pm 0,93$ & $2,83 \pm 1,37$ & $<0,05$ \\
\hline Терминальная длит. ОК ПДЕ, мс & $5,63 \pm 1,51$ & $4,80 \pm 1,41$ & $<0,01$ \\
\hline Фазы ОК ПДЕ & $1,32 \pm 0,91$ & $1,39 \pm 0,86$ & $>0,05$ \\
\hline Турны ОК ПДЕ & $2,05 \pm 1,69$ & $2,26 \pm 1,50$ & $>0,05$ \\
\hline Время нарастания ОК ПДЕ, мкс & $536,7 \pm 244,9$ & $578,3 \pm 333,3$ & $>0,05$ \\
\hline
\end{tabular}

Регистрировались единичные ПФ. Однако, при исследовании на 21-й день от момента введения, спонтанная активность не регистрировалась. Это свидетельствует о локальном воздействии препарата, в используемой дозировке, непосредственно на триггерную зону горизонтальной порции трапециевидной мышцы, не выключая тем самым всю скелетную мышцу из нормальной деятельности, что, в конечном итоге, не приводит к изменению двигательного стереотипа и перегрузке других мышц.

Как следует из таблицы 2, уже к 7-му дню имелись признаки реорганизации ДЕ. Отмечалась тенденция снижения амплитуды и смещения гистограммы распределения потенциалов по длительности влево, в сторону меньших величин. Так, нормализованная длительность потенциалов была в пределах нормальных величин в 92\% случаев, т. е. длительность ПДЕ не превышала $\pm 30 \%$ от величины среднего показателя. Выявлены статистически достоверные изменения временных характеристик спайкового компонента потенциала в виде пространственного перераспределения мышечных волокон в ДЕ: увеличения длительности и укорочения терминальной части основного компонента.

Через неделю после введения БТА, регистрируются потенциалы с длительностью спайковой части более 3 мс. Если до введения препарата длительность ОК ПДЕ в 90\% случаев была в диапазоне 1-3 мс, то через неделю после введения лишь около 70\% всех потенциалов соответствовало этому диапазону, а 31\% превышал длительность ОК ПДЕ в 3 мс.

Данные, представленные в таблице 3, свидетельствуют о значительных изменениях, регистрируемых через месяц после введения БТА. Нормализованная длительность потенциалов

Таблица 3

Сравнительный анализ средних величин (M士SD) параметров ПДЕ, регистрируемых в миофасциальной триггерной зоне, до и через месяц после введения ботулотоксина типа А

\begin{tabular}{|l|l|l|l|}
\hline Параметры & Исходные значения & $\begin{array}{l}\text { Через месяц } \\
\text { после введения }\end{array}$ & P \\
\hline Длительность ПДЕ в \% & $94,78 \pm 13,05$ & $81,68 \pm 19,04$ & $<0,001$ \\
\hline АмПлитуда, мКВ & $965,52 \pm 797,11$ & $826,17 \pm 627,61$ & $>0,05$ \\
\hline Фазы ПДЕ & $3,47 \pm 1,19$ & $2,92 \pm 0,68$ & $<0,01$ \\
\hline Турны ПДЕ & $3,97 \pm 2,16$ & $2,58 \pm 0,87$ & $<0,001$ \\
\hline Латентность ОК ПДЕ, мс & $3,03 \pm 1,12$ & $2,54 \pm 0,75$ & $<0,05$ \\
\hline Длительность ОК ПДЕ, мс & $2,30 \pm 0,93$ & $1,75 \pm 0,67$ & $<0,001$ \\
\hline Терминальная длительность ОК ПДЕ, мс $5,63 \pm 1,51$ & $5,20 \pm 2,00$ & $>0,05$ \\
\hline Фазы ОК ПДЕ & $1,32 \pm 0,91$ & $1,15 \pm 0,91$ & $>0,05$ \\
\hline Турны ОК ПДЕ & $2,05 \pm 1,69$ & $1,90 \pm 1,01$ & $<0,05$ \\
\hline Время нарастания ОК ПДЕ, мкс & $536,7 \pm 244,9$ & $333,3 \pm 209,7$ & $<0,001$ \\
\hline
\end{tabular}


была в пределах $\pm 30 \%$ лишь в $68 \%$ случаев; большинство из них распределились в границах от 70 до 100. В 21\% случаев распределение потенциалов по длительности было в пределах от 60 до 70\%. Из вышеприведенного следует, что имелось смещение гистограммы распределения потенциалов по длительности влево. Выявлены статистически достоверные изменения количественных характеристик - в виде уменьшения числа фаз и турнов потенциала и их спайковой части, что практически соответствовало аналогичным параметрам в мышцах здоровых людей. Наблюдалась нормализация латентности и длительности спайковой части потенциала (в норме $2,7 \pm 1,3$ мс и $2,0 \pm 0,6$ мс, соответственно).
Следует отметить и тот факт, что наблюдалось значительное укорочение времени нарастания ОК ПДЕ через месяц после введения БТА. Более чем в половине всех потенциалов, время нарастания потенциала было от 100 до 200 мкс.

Таким образом, через месяц после введения препарата отмечалось изменение, а именно, нормализация, тех параметров ПДЕ, которые наиболее четко реагируют на происходящую функциональную реорганизацию ДЕ. Укорочение длительности ПДЕ и смещение гистограммы распределения потенциалов по длительности влево, свидетельствует о преимущественном денервационном процессе с достаточной компенсаторной реиннервацией.

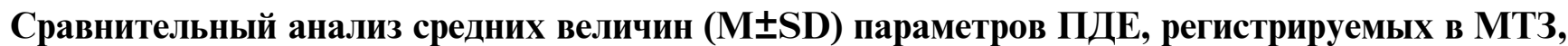 до и через 4 месяца после введения ботулотоксина типа $А$}

\begin{tabular}{|l|l|l|l|}
\hline Параметры & Исходные значения & $\begin{array}{l}\text { Через 4 месяця } \\
\text { после введения }\end{array}$ & P \\
\hline Длительность ПДЕ, \% & $94,78 \pm 13,05$ & $90,86 \pm 15,98$ & $>0,05$ \\
\hline Амплитуда, мКВ & $965,52 \pm 797,11$ & $1000,43 \pm 824,69$ & $>0,05$ \\
\hline Фазы ПДЕ & $3,47 \pm 1,19$ & $3,56 \pm 1,40$ & $>0,05$ \\
\hline Турны ПДЕ & $3,97 \pm 2,16$ & $4,87 \pm 2,59$ & $<0,05$ \\
\hline Латентность ОК ПДЕ, мс & $3,03 \pm 1.12$ & $3,28 \pm 1,22$ & $>0,05$ \\
\hline Длительность ОК ПДЕ, мс & $2,30 \pm 0,93$ & $2,66 \pm 1,25$ & $>0,05$ \\
\hline Терминальная длит. ОК, мс & $5,63 \pm 1,51$ & $4,39 \pm 1,29$ & $<0,01$ \\
\hline Фазы ОК ПДЕ & $1,32 \pm 0,91$ & $1,73 \pm 1,18$ & $<0,05$ \\
\hline Турны ОК ПДЕ & $2,05 \pm 1,69$ & $3,07 \pm 2,31$ & $<0,001$ \\
\hline Время нарастания ОК, мкс & $536,7 \pm 244,9$ & $333,0 \pm 169,3$ & $<0,001$ \\
\hline
\end{tabular}

Анализ таблицы 4 показал, что через 4 месяца после введения препарата намечалась тенденция к восстановлению параметров ПДЕ к исходным величинам. Имеются различия лишь в наиболее динамичных параметрах, реагирующих на минимальные изменения функционального состояния ДЕ. Следует отметить, что среднее значение и гистограмма распределения времени нарастания спайковой части потенциала практически не изменилась, по сравнению с данными, зарегистрированными через месяц после введения.

Данные таблицы 5 свидетельствуют о восстановлении практически всех изучаемых параметров к исходным величинам через год после введения препарата. Отсутствуют статистически достоверные различия параметров ПДЕ и их спайковой части при межгруп- повом сравнении - до введения препарата и через год после введения БТА.

В серии выполненных нами исследований, регистрация отдельных ПДЕ - как с уменьшенной длительностью и амплитудой, свидетельствующая о наличии временной денервации, так и ПДЕ с увеличенной длительностью и высокой амплитудой, характеризующая реиннервацию, - дают основание рассматривать данное патологическое состояние с позиции денервационно-реиннервационного процесса. Длительность ПДЕ отражает дисперсию распространяющихся одиночных потенциалов МВ в пределах изучаемой ДЕ. Дисперсия увеличивается со спраутингом нерва и различиями в диаметре МВ. Стимулом для спраутинга могли быть, как продукты распада дегенерирующего аксона, так и денервированного МВ. 
Таблица 5

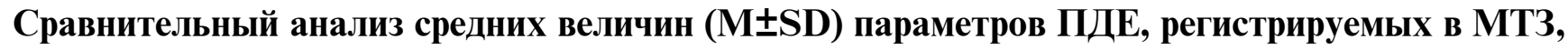
до и через год после введения ботулотоксина типа A

\begin{tabular}{|l|l|l|l|}
\hline Параметры & Исходные значения & $\begin{array}{l}\text { Через год } \\
\text { после введения }\end{array}$ & P \\
\hline Длительность ПДЕ, \% & $94,78 \pm 13,05$ & $101,32 \pm 15,95$ & $>0,05$ \\
\hline Амплитуда, мкВ & $965,52 \pm 797,11$ & $924,25 \pm 488,00$ & $>0,05$ \\
\hline Фазы ПДЕ & $3,47 \pm 1,19$ & $3,39 \pm 0,93$ & $>0,05$ \\
\hline Турны ПДЕ & $3,97 \pm 2,16$ & $3,68 \pm 1,65$ & $>0,05$ \\
\hline Латентность ОК ПДЕ, мс & $3,03 \pm 1.12$ & $3,42 \pm 1,06$ & $>0,05$ \\
\hline Длительность ОК ПДЕ, мс & $2,30 \pm 0,93$ & $2.52 \pm 0.91$ & $>0,05$ \\
\hline Терминальная длительность ОК ПДЕ, мс $5,63 \pm 1,51$ & $5,28 \pm 1,65$ & $>0,05$ \\
\hline Фазы ОК ПДЕ & $1,32 \pm 0,91$ & $1,19 \pm 0,40$ & $>0,05$ \\
\hline Турны ОК ПДЕ & $2,05 \pm 1,69$ & $2.25 \pm 1,65$ & $>0,05$ \\
\hline Время нарастания ОК ПДЕ, мкс & $536,7 \pm 244,9$ & $387,5 \pm 164,1$ & $>0,05$ \\
\hline
\end{tabular}

Реорганизация структуры ДЕ в зоне миофасциального триггера, на различных сроках проведения исследования, подтверждена при анализе плотности распределения МВ отдельных ДЕ (рис. 1).

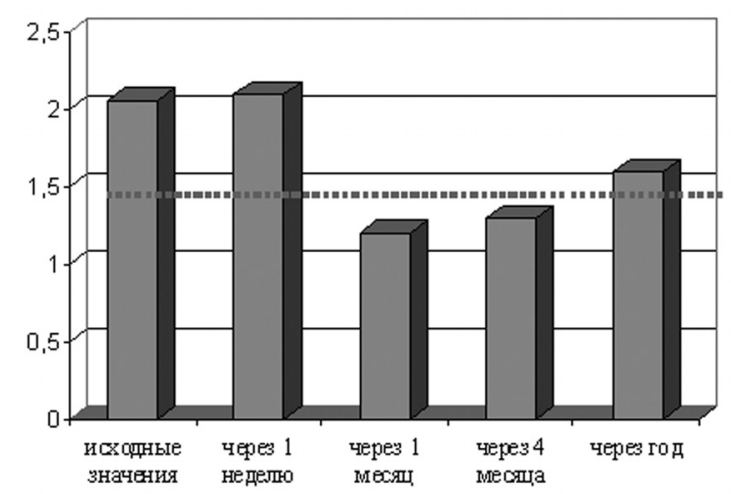

Рис. 1. Гистограмма распределения плотности мышечных волокон в МТЗ до и в различные периоды после введения БТА. Пунктирной линией обозначена норма (1.48, SD 0.3).

Известно, что средняя величина плотности MB в мышцах здоровых людей, рассчитываемая на основании подсчета числа потенциалов MB, равна примерно 1,47 с небольшими вариациями, в зависимости от возраста и мышцы [43]. В контрольной группе здоровых испытуемых, плотность МВ соответствовала 1.48, SD 0.3. Учитывая тот факт, что у субъектов до 10ти лет и после 60-ти лет, в целом, плотность МВ несколько выше, возрастные критерии отбора больных ограничивались 50-ю годами.

Исходные значения плотности мышечных волокон в МТ3 составили 2.05, SD 0.26. Реги- стрировались потенциалы отдельного мышечного волокна с одним, но чаще - с двумя, тремя и четырьмя спайками. Увеличение плотности МВ обычно отражает наличие коллатерального спраутинга. Через неделю после введения БТА, изменения плотности МВ не наблюдалось. Максимальное снижение плотности МВ, которое сопоставимо, и не различалось от значений нормы в контрольной группе исследуемых, наблюдалось через месяц и 4 месяца от введения БТА. Через год после введения препарата наблюдалась тенденция к восстановлению плотности MB (1.6, SD 0.27), но, показатель был достоверно ниже исходной величины.

Отмечено увеличение межимпульсного интервала в МТ3, по сравнению с контрольной группой (нормой), однако, результаты были статистически недостоверны, что не дает возможность их обсуждение в рамках данного исследования. Следует отметить, что увеличение джиттера не является специфичным признаком, характеризующим пре- или постсинаптическое нарушение нервно-мышечной передачи.

В соответствии с результатами математического моделирования ПДЕ, имеется зависимость параметров ПДЕ от числа и размеров MB, непосредственно прилегающих к отводящей поверхности электрода, или отдаленных от них на расстояние не более 500 мкм. Остальные, более отдаленные волокна формируют медленные колебания потенциала, предшествующие спайковой части ПДЕ или 
следующие за ней [29]. Результаты сканирующей ЭМГ также свидетельствуют о том, что только небольшая часть волокон ДЕ формирует спайковый компонент ПДЕ. В этой связи, становится понятным раннее изменение параметров спайкового компонента ПДЕ уже на 1-ой неделе после введения БТА. Показано, что наиболее ранними изменениями ОК ПДЕ являются нарастание амплитуды, длительности и числа турнов, причем, изменения этих параметров коррелируют между собой в достаточно высокой степени [10].

Обращает на себя внимание корреляция между изменением плотности волокон в ДЕ и увеличением числа турнов ОК ПДЕ (рис. 2).

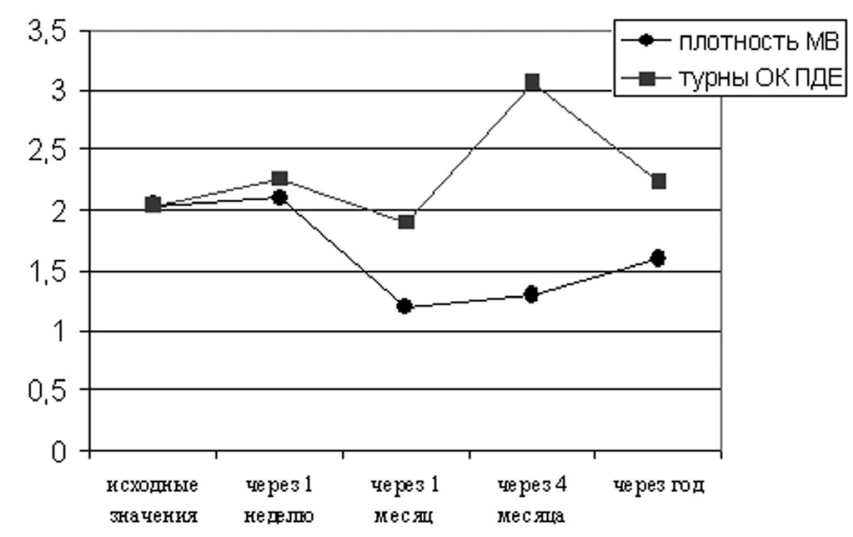

Рис 2. Изменение плотности мышечных волокон ДЕ и числа турнов спай-ковой части потенциала, регистрируемых в МТЗ, до и в различные периоды после введения БТА.

Известно, что средняя плотность мышечных волокон ДЕ в мышцах здоровых людей, измеряемая в условных величинах, составляет $1,47 \pm 0,3$, с индивидуальными колебаниями от 1-й до 3-х в одной ДЕ. Среднее число турнов ОК ПДЕ в мышцах здоровых людей имеет очень близкую величину и составляет

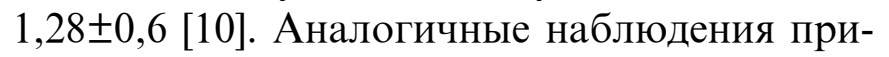
водятся и в других исследованиях $[5,7]$.

Исходное значение числа турнов в МТЗ составило 2,05 $\pm 1,69$, а плотности МВ в МТ3 $2,05 \pm 0,26$. К концу первого месяца введения препарата, регистрировалось снижение как числа турнов, так и уменьшение плотности MB в МТ3 $(1,90 \pm 1,01$ и $1,2 \pm 0,4$, соответственно). К 4-му месяцу наблюдалось значительное нарастание числа турнов в МТЗ, с последую- щей стабилизацией до исходной величины.

Анализ клинических данных выявил, что положительная динамика состояния больных намечалась к концу первой недели после введения препарата, и к концу первого месяца отмечалось восстановление плотности мышечной ткани; практически нивелировался триггерный феномен. В течение четырех месяцев не отмечалось рецидива со стороны исследуемых мышц. Лишь у ряда пациентов, при воздействии неблагоприятных факторов, - преимущественно, позно-тонические перегрузки и эмоциональный стресс, - наблюдалось формирование латентных МТЗ в данной области. Следовательно, возможно увеличить интервал действия препарата вплоть до года, тогда как по многочисленным рекомендациям, он составляет 3-4 месяца, а при дополнительном воздействии методов коррекции двигательного стереотипа, вполне можно и отказаться от повторного применения препарата.

Таким образом, проведенное исследование по применению препарата БТА у больных с миофасциальным болевым синдромом, продемонстрировало положительное действие ботулотоксина типа А на электрофизиологические параметры, отражающие функциональное состояние периферического нейромоторного аппарата, а клинический эффект облегчил состояние пациентов, и позволил не применять в течение всего периода каких-либо препаратов из огромного числа фармакологических средств и мануальных пособий.

Локальное введение небольших доз препарата БТА непосредственно в зону триггерной точки, позволили избежать быстрой диффузии, клинически проявляющуюся генерализованной мышечной слабостью и нейрофизиологически активной денервацией, что обычно наблюдается при введении БТА в относительно большом объеме в двигательную точку мышцы.

В заключение хочется отметить, что лечение тонически напряженных мышц препаратом диспорт, позволяет в несколько раз увеличить процент излеченных пациентов от заболеваний, сопровождающихся мышечным спазмом, и, несомненно, будет иметь значительный успех терапии миофасциальной боли. 
Следует рекомендовать препараты БТА к широкому применению в клинической невроло-

\section{ЛИТЕРАТУРА}

1. Алексеев В. В., Солоха О. А. Миофасциальный болевой синдром: применение ботокса // Неврологический журнал. - 2001. - №2. - С. 30-35.

2. Артемьев Д. В., Орлова О. Р., Моренкова А.Э. Использование ботокса в медицин-ской практике // Неврологический журнал. - 2000. - №4. - С. 46-52. 3. Вейн А. М. Болевые синдромы в неврологической практике. М.: МЕД пресс-информ, - 2001. - 368 с. 4. Гехт Б. М., Касаткина Л. Ф., Санадзе А. Г., Строков И. А. Трофический потенциал мотонейрона и проблема компенсаторной иннервации в патоогии // Механизмы нейрональной регуляции мышечной функции. - Л.: Медицина, - 1988. - С. 53-78.

5. Девликамова Ф. И. Нейрофизиологическая характеристика двигательных единиц скелетных мышц у больных с миофасциальным болевым синдромом: Автореф. дис. ... канд. мед. наук. - Казань, - 1996. - 23 с.

6. Девликамова Ф. И., Иваничев Г. А., Касаткина Л. Ф. Функциональное состояние двигательных единиц скелетных мышц в условиях формирования миофасциального триггерного пункта // Вертеброневрология. - 1998. - №1. - С. 28-33.

7. Devlikamova F. I., Kasatkina L. F. Single fiber electromyography in studies of myofascial trigger point // J. of Musculoskeletal pain. - 1998. - Vol.6, №2 (Suppl.). - P. 21.

8. Иваничев Г. А. Болезненные мышечные уплотнения. - Казань: Изд-во Каз. Универ-ситета, 1990. - $156 \mathrm{c}$.

9. Касаткина Л. Ф. Функциональное состояние двигательных единиц скелетных мышц при хронических заболеваниях мотонейронов и их аксонов // Неврологический вест-ник. - 1995. - Т. 27, №№ 1-2. - С. 5-11.

10. Касаткина Л. Ф. Особенности течения денервационно-реиннервационного процесса при различных уровнях поражения периферического нейромоторного аппарата (клинико-патофизиологическое исследование): Автореф. дис. ... докт. биол. наук. - М., - 1996. - 46 с.

11. Орлова О. Р. Фокальные дистонии: клиника, патогенез, лечение с использованием токсина ботулизма: Автореф. дис. ... докт. мед. наук. - М., 2000. - 43 c.

12. Орлова О. Р., Яхно Н. Н. Применение ботокса (токсина ботулизма типа А) в клини-ческой практике. - М.: Каталог, - 2001. - 208 с. гии, как обоснованное патогенетическое средство при миофасциальных болевых синдромах.

13. Торопина Г. Г., Солоха О. А., Алексеев В. В. Соматосенсорные вызванные потенциалы у больных с синдромом замороженного плеча до и после лечения ботоксом // Неврологический журнал. - 2002. - №5. - С. 39-43.

14. Хабиров Ф. А., Хабиров Р. А. Мышечная боль - Казань: Книжный дом - 1995. - 208 с.

15. Хайман Н .М. Лечение дистонии и спастичности ботулиническим токсином - Санкт-Петербург, - 2000. - 24 с.

16. Acquadro M. A., Borodic G. E. Treatment of myofascial pain with botulinum A toxin (letter) // Anesthesiology. - 1994. - Vol.80. - P. 705-706.

17. Alejandra Pereda C, Us?n Jaeger J, Carmona L. Systematic review: can botulinum toxin be recommended as treatment for pain in myofascial syndrome? // Reumatol Clin. - 2006. - Vol.2(4). - P. 173182.

18. Argoff C. E. A focused review on the use of botulinum toxins for neuropathic pain // Clinical Journal of Pain - 2002. - Vol.18, №6. - P. 22-29.

19. Brown M. C., Ironton R. Sprouting and regression of neuromuscular synapsesin partially denervated of neuromuscular synapses in partially denervated mammalian muscles // J. Physiol. (London). - 1978. Vol.278. - P. 325-348.

20. Buchthal F. An introduction to electromyography. - Copenhagen: Gyldendal, 1957. - 43 p.

21. Cheshire W. P., Abashjan S. W., Mann J. D. Botulinum toxin in the treatment of myofascial pain syndrome // Pain. - 1994. - Vol.59. - P. 65-69.

22. Childers M. K., Kornegay J. N., Aoki R., et al. Evaluating motor end-plate-targeted injec-tions of botulinum toxin type A in a canine model // Muscle Nerve. - 1998. - Vol.21. - P. 653-655.

23. Climent J. M., Kuan T. S., Fenollosa P., MartinDel-Rosario F. Botulinum toxin for the treatment of myofascial pain syndromes involving the neck and back: a review from a clinical perspective. // Evid Based Complement Alternat Med. - 2013. - Vol.2013, Article ID 381459.

24. Difazio M., Jabbari B. A focused review of the use of botulinum toxins for low back pain // Clinical Journal of Pain - 2002. - Vol.18, №6. - P. 155-162.

25. Duggan M. J., Quinn C. P., Chaddock J. A., et al. Inhibition of release of neurotransmitters from rat dorsal root ganglia by a novel conjugate of a Clostridium botulinum toxin A endopeptidase frag- 
ment and Erythrina cristagalli lectin. // J Biol Chem. - 2002. - Vol.277(38). - P. 34846-34852.

26. Ferrante F. M., Bearn L., Rothrock R., King L. Evidence against trigger point injection technique for the treatment of cervicothoracic myofascial pain with botulinum toxin type A. // Anesthesiology. - 2005. Vol.103. - P. 377-383.

27. Gerwin R. Botulinum toxin treatment of myofascial pain: a critical review of the literature. // Curr Pain Headache Rep. - 2012. - Vol.16(5). - P. 413-422. 28. Giladi N. The non-neuromuscular effects of Botulinum toxin // Eu. J. Neurol. - 1995. - Vol.2. - P. 11-16. 29. Gilai A .N. Analysis of turns and amplitude in EMG // Computer-Aided Electromyography and Expert Systems / Ed. Desmedt J. E. - Elsevier Science Publishers B. V., 1989. - Chap-ter 12. - P. 143-160. 30. G?bel H., Heinze A., Reichel G., Hefter H., Benecke R. Efficacy and safety of a single botulinum type A toxin complex treatment (Dysport) for the relief of upper back myofascial pain syndrome: results from a randomized double-blind placebo-controlled multicentre study. Pain. - 2006. - Vol.125(1-2) - P. 82-88. 31. Gobel H., Heinze A., Heinze-Kuhn K, Austermann $\mathrm{K}$. Botulinum toxin $\mathrm{A}$ for the treatment of headache disorders and pericranial pain syndromes// Nervenarzt.- 2001.- Vol. 72 (4). - P. 261-274.

32. Guyer B. M. Mechanism of botulinum toxin in the relief of chronic pain // Cur. Rev. Pain. - 1999. Vol.3. - P. 27-431.

33. Hagenah R., Benecke R., Wiegand H. Effects of type A botulinum toxin on the cholinergic transmission at spinal renshaw cells and on the inhibitory action at Ia inhibitory interneurones // NaunynSchmiedebergs Arch. Pharmacol. - 1977. - Vol.299. P. 267-272.

34. Hong C.Z., Simons D.G. Pathophysiologic and electrophysiologic mechanisms of myofascial trigger points // Arch. Phys. Med. Rehabil. - 1998. - Vol.79. - P. 863-872.

35. Hubbard D. R., Berkoff G. M. Myofascial trigger points show spontaneous needle EMG activity // Spine. - 1993. - Vol.18. - P. 1803-1807.

36. Kimura J. End-plate activities // Electrodiagnosis in diseases of nerve and muscle / Ed. F. A. Davis. Philadelphia, - 1989. - Vol.2. - P. 231-233.

37. Kuan T. S., Chen J. T., Chen S. M., Chien C. H., Hong C. Z. Effect of botulinum toxin on endplate noise in myofascial trigger spots of rabbit skeletal muscle // Am. J. Phys. Med. Rehabil. - 2002. - Vol.81, №7. - P. 512-523.

38. Lang A. M. Botulinum toxin therapy for myofascial pain disorders // Curr. Pain Headache Rep. -
2002 - Vol.6(5). - P. 355-360.

39. On A. Y., Kirazli Y., Kismali B., Aksit R. Mechanisms of action of phenol block and botulinus toxin Type A in relieving spasticity: electrophysiologic investigation and follow-up. // Am. J. Phys. Med. Rehabil. - 1999. - Vol.78(4). - P. 344-349.

40. Porta M. Botulinum toxin type A injections for myofascial pain syndrome and tension-type headache // Eur. J. Neurol. - 1999. - Vol.6 (suppl 4). - P. 103-109. 41. Porta M., Valla P., Gamba M., Ferro M. T. Muscle spasm, myofascial pain and treatment by botulinum toxin // J. of Musculoskeletal pain. - 1998. Vol.6, №2 - P. 54.

42. Preston D. C., Shapiro B. E. Needle electromyography: Fundamentals, normal and abnormal patterns // Neurologic Clinics. - 2002. - Vol.20, №2.

43. Rollnik J. D., Dengler R. Botulinum toxin (DYSPORT) in tension-type headaches // Acta Neurochir 2002. - Vol.79 - P. 123-126.

44. Simons D. G., Hong C-Z., Simons L. S. Endplate potentials are common to midfiber myo-fascial trigger points // Am. J. Phys. Rhabil. - 2002. - Vol.81., №3. - P. 212-222.

45. Simons D. G., Trevell J. G., Simons L. S. Myofascial pain and dysfunction. The trigger point manual. - Williams \& Wilknis, - 1999. - 1038 p.

46. Smith H. S., Audette J., Royal M. A. Botulinum toxin in pain management of soft tissue syndromes // Clinical Journal of Pain - 2002. - Vol.18 (Suppl. 6). P. 147-154.

47. Soares A, Andriolo R. B., Atallah A. N., da Silva E. M. Botulinum toxin for myofascial pain syndromes in adults. // Cochrane Database Syst Rev. - 2012.

48. Stalberg E., Andreassen S., Falk B., Lang H., et al. Quantitative analysis of individual motor unit potentials: a proposition for standardized terminology and criteria for measurement // J. Clin. Neurophysiol. - 1986. - №3. - P. 313-348.

49. Stalberg E., Trontelj J. V. Abnormal discharges generated within the motor unit as observed with single-fiber electromyography. - Oxford (UK): Oxford University Press, - 1982. - 474 p.

50. Thiele B., Stalberg E. Single fibre EMG findings in polyneuropathies of different etiology //J. Neurol. Neurosurg. Psychiat. - 1975. - Vol.38. - P. 881-887.

51. Wheeler A. H., Goolkasian P., Gretz S. S. A randomized, double-blind, prospective pilot study of botulinum toxin injection for refractory, unilateral cervicothoracic, paraspinal, myofascial pain syndrome // Spine. - 1998. - Vol.23. - P. 1662-1667.

52. Wiederholt W. C. "End-plate noise" in electromyography // Neurology. - 1970. - Vol.20. - P. 214-224. 


\title{
XÜLASə
}

\section{MİOFASSİAL AĞRI SİNDROMUNUN MÜALİCəSINDӘ A TIP BOTULIN TOKSIN PREPARATININ ISTIFADOSI}

\author{
Devlikamova F.í., Roqojin A.A. \\ Kazan dövlat tibb akademiyast, Kazan, RF
}

Miofassial ağrı sindromunun müalicəsində A tip botulotoksin preparatının istifadəsi bir çox nəzəri zəminlərə malik olsa da, kliniki effektivliyi hələ də sübut olunmamış qalır. Trapesiyayabənzər əzələnin horizontal porsiyasında aktiv miofassial trigger zonaları (MTZ) ilə 50 yaşına qədər 12 pasiyent tədqiq edilmişdir. Bu zonalara A tip botulotoksin yeridilmişdir. Preparat yeridilməmişdən əvvəl, 1 həftə, 1, 4, 12 ay sonra MTZ-da standart iynəli EMQ və tək əzələ lifinin EMQ-sı aparılmışdır. Bir ay sonra hərəki vahidin potensialının (HVP) müddətinin qisalması və potensialların paylanması histoqrammının müddətinə görə yayılmasının sola yerdəyişməsi aşkarlanmışdır. Preparatın yeridilməsindən 4 ay sonra HVP-nın parametrlərinin bərpası qeyd edilmişdir. İnyeksiyadan 1 il sonra HVP-nın parametrləri əvvəlkilərdən fərqlənməmişdir. Beləliklə, aparılmış tədqiqat A tip botulotoksinin periferik neyromotor apparatın funksional vəziyyətini əks etdirən MTZ-nın elektrofizioloji parametrlərinə müsbət təsirini göstərmişdir.

Açar sözlər: miofassial ağrı sindromu, trigger nöqtələri, A tip botulinotoksin, elektromioqrafiya, hərəkət vahidi, əzələ lifi.

\section{ABSTRACT \\ USE OF THE PREPARATION OF BOTULINUM TOXIN TYPE A IN THE TREATMENT OF MYOFASCIAL PAIN SYNDROME}

\author{
Devlikamova F.I., Rogojin A.A. \\ Kazan State Medical Academy, Department of Neurology and manual therapy, Kazan, Russia
}

Sufficient amount of experimental data suggests usage of botulinum toxin type A in the treatment of myofascial pain, but there are still not enough data about clinical efficacy and long term neurophysiologic changes. We studied 12 patients younger 50 with active MTP in upper trapezius. Injections of of BTA were done in each MTP. Standard concentric needle EMG and single fiber EMG was done in the area of MTP before injection, one week and 1, 4, and 12 months after. MUP duration was decreased and MUP duration histogram was moved to the left one month after injection. 4 months after injection recovery of MUP parameters was observed. One year after injections MUP parameters didn't differ from basic. Therefore our investigation demonstrated changes of EMG parameters in MTP after BTA injection.

Key words: Myofascial pain syndrome, myofascial trigger zone, botulin toxin of the type A, electromyography, motor unit, muscle fiber

Redaksiyaya daxil olub: 12.07.2013

Çapa tövsiy olunub: 10.08 .2013

Rəyçi: X.I.Hasanov, t.ü.f.d. 